\title{
Seroprevalence and risk factors of Hepatitis B and Hepatitis C infections among pregnant women in the Asante Akim North Municipality of the Ashanti region, Ghana; a cross sectional study.
}

\author{
Richard Ephraim¹, Isaac Donko², Samuel A. Sakyi ${ }^{3}$ Joyce Ampong ${ }^{1}$, Hope Agbodjakey ${ }^{1}$
}

\author{
1. Department of Medical Laboratory Technology, School of Allied \\ Health Sciences, College of Health and Allied Sciences, University of Cape Coast \\ 2. Department of Laboratory Technology, University of Cape Coast \\ 3. Department of Molecular Medicine, School of Medical Sciences, \\ College of Health Sciences, Kwame Nkrumah University of Science and Technology
}

\begin{abstract}
Background: Viral hepatitis is a serious public health problem affecting billions of people globally with maternal-fetal transmission on the rise.

Objectives: This study sought to determine the prevalence and factors associated with hepatitis B virus (HBV) and hepatitis $\mathrm{C}$ virus (HCV) infections among pregnant women in the Asante Akim North Municipality, in the Ashanti region of Ghana. Methods: In this cross-sectional study 168 pregnant women were recruited from the Agogo Presbyterian hospital. Blood samples were collected for the detection of Hepatitis B Surface Antigen (HBsAg) and anti-HCV antibodies. A pretested questionnaire was used to obtain demographic data and identify the risk factors associated with the two infections.

Results: Of the 168 participants studied, $16(9.5 \%)$ tested positive for HBV and 13 (7.7\%) tested positive for HCV representing $9.5 \%$ and $7.7 \%$ respectively. A participant tested positive for both HBV and HCV co-infection representing $0.6 \%$. Undertaking blood transfusion, tattooing and sharing of needles were associated with hepatitis $\mathrm{C}$ infection $(\mathrm{P}=0.001)$. HBV was not associated with any of the risk factors $(\mathrm{P}>0.05)$.

Conclusion: Our findings suggest a high prevalence of hepatitis B and hepatitis $\mathrm{C}$ among pregnant women; blood transfusion, tattooing and sharing of hypodermic needles were associated with hepatitis $\mathrm{C}$ infection. Measures to reduce the disease and transmission burden must be introduced.
\end{abstract}

Keywords: Hepatitis B, Hepatitis C, pregnant women, seroprevalence, risk factors, Ghana.

DOI: http://dx.doi.org/10.4314/ahs.v15i3.2

Cite as: Ephraim R, Donko I, Sakyi SA, Ampong J, Agbodjakey H. Seroprevalence and risk factors of Hepatitis B and Hepatitis C infections among pregnant women in the Ashanti Akim North Municipality of the Ashanti region, Ghana; a cross sectional study. Afri Health Sci. 2015;15(3):709-13. doi: http:// dx.doi.org/10.4314/abs.v15i3.2

\section{Introduction}

Hepatitis B virus (HBV) and hepatitis $\mathrm{C}$ virus (HCV) infections are serious public health issues with different prevalence rates worldwide. About one fifth of the 2 billion people infected with $\mathrm{HBV}$ across the globe have chronic infection $^{1,2}$. World Health Organization (WHO) estimates indicate that about 200 million people have $\mathrm{HCV}$ infection across the globe ${ }^{3,4}$. HBV and HCV are

\section{Corresponding author: \\ Richard Ephraim \\ Department of Medical Laboratory Technology, School of Allied Health Sciences, College of Health and Allied Sciences, University of Cape Coast \\ Email: kdephraim@yahoo.com/ \\ kobinadadzieephraim@gmail.com}

contagious diseases that can be transmitted vertically from mothers to their neonates or horizontally through blood products and body secretions ${ }^{5}$. Mother-to- child transmission remains one of the commonest routes by which HBV infection is contracted worldwide. ${ }^{6}$ The World Health Organization (WHO) estimates that 3\% of the world's population has chronic hepatitis $\mathrm{C}$ infection. Most of these cases occur in Africa, which has the highest HCV infection prevalence rate ${ }^{7}$. Between 1999 and 2002, an estimated 4.1 million people in the United States were infected with HCV, and of these, 3.2 million had chronic infection ${ }^{8}$.

Acute HBV infection during pregnancy is less severe and is not directly associated with increased mortality or teratogenicity ${ }^{9,10}$. However, increased incidences of low birth weight and prematurity in infants born to mothers with acute HBV infection have been recorded ${ }^{9,11}$. Furthermore, acute HBV infection in early pregnancy has 
been associated with a $10 \%$ perinatal transmission rate ${ }^{11}$. Transmission rates (as high as 60\%) have been reported to increase significantly if acute infection occurs at or near the time of delivery ${ }^{10}$.

In light of the aforementioned this study sought to determine the prevalence and factors associated with HBV and HCV infections among pregnant women at the Agogo Presbyterian hospital in the Ashanti region of Ghana. Screening pregnant women for hepatitis B and $\mathrm{C}$ can give a reliable prevalence of the disease in this population and provide an avenue for preventing mother to child transmission of the virus.

\section{Subjects and methods}

\section{Study design/study site}

This cross-sectional hospital based study was conducted at the Agogo Presbyterian hospital from December 2012 to February 2013. The hospital is a referral centre located in the Asante Akim North District of the Ashanti region of Ghana. It provides antenatal and other specialized obstetric services for the inhabitants of the district and beyond. This district is a predominantly farming community.

\section{Study population/sampling technique}

The study population comprised all pregnant women receiving antenatal care at the Agogo Presbyterian hospital, in the Asante Akim North municipality. We used consecutive sampling to recruit 168 eligible pregnant women after we had explained the significance of the study to the participants who visited the health facility within the study period. Women with a previous history of any form of liver disease, diabetes and pre-eclampsia were excluded from the study.

\section{Socio-demographic data}

We obtained informed written consent from participants of the study and administered a pre-tested questionnaire to obtain socio-demographic and obstetric information,such as age, parity, educational background and marital status. Other data on the risk factors of possible routes of transmission of HBV and HCV like sharing of toothbrush, haemodialysis treatment, history of abortions, multiple sexual partners, history of previous blood transfusions and other blood products, history of intravenous drug use, history of tattooing, history of HBV vaccination was obtained.

\section{Laboratory methods \\ Blood sample collection}

Three milliliters ( $3 \mathrm{mls}$ ) of venous blood was collected from each participant through venipuncture, dispensed into serum separator tubes, allowed to clot and centrifuged at a relative centrifugal force (RCF) of 1000$1500 \mathrm{~g}$ for 10 minutes. The serum aliquots were stored at $-20^{\circ} \mathrm{C}$ until ready for use.

\section{$\mathrm{HBV}$ and $\mathrm{HCV}$ testing}

Separate strips (Dia Spot Rapid One-step Test Strip, United Kingdom) were used to detect HBsAg and anti-HCV antibodies in the serum of participants in accordance with the manufacturers' instructions.

\section{Statistical analysis}

Data was entered into Excel worksheet and analyzed using SPSS version 16 (Statistical Package for Social Sciences). Also Chi - square model was conducted to determine the significance of the associations between the possible risk factors and their infections due to the non-parametric nature of the data P-value $<0.05$ was considered significant.

\section{Ethical approval}

Ethical consent was sought from the Institutional Review Board of the University Cape Coast (UCCIRB) and the hospital ethical committee. Informed consent was obtained from each participant prior to commencement of the study.

\section{Results}

Table 1 shows the prevalence of HBV and HCV infection among the study participants. For HBV 16 participants $(9.5 \%)$ tested positive whereas $13(7.7 \%)$ tested positive for HCV. Only 1 participant $(0.6 \%)$ had mixed infection of HbsAg and HCV. 
Table 1: Baseline characteristics of participants and prevalence of viral hepatitis infection

\begin{tabular}{|c|c|}
\hline Variable & $\begin{array}{l}\mathbf{N}(\%) \\
(\mathrm{n}=168)\end{array}$ \\
\hline \multicolumn{2}{|c|}{ Age group n (\%) } \\
\hline $10-14$ & $2(1.2)$ \\
\hline $15-19$ & $12(7.1)$ \\
\hline $20-24$ & $43(25.6)$ \\
\hline $25-29$ & $55(32.7)$ \\
\hline $30-34$ & $30(17.9)$ \\
\hline $35-40$ & $26(15.5)$ \\
\hline \multicolumn{2}{|c|}{ Education $n$ (\%) } \\
\hline None & $15(8.9)$ \\
\hline Primary & $105(62.5)$ \\
\hline Secondary & $24(14.3)$ \\
\hline Tertiary & $24(14.3)$ \\
\hline \multicolumn{2}{|c|}{ Occupation n (\%) } \\
\hline None & $30(17.9)$ \\
\hline Formal & $17(10.1)$ \\
\hline Informal & $121(72.0)$ \\
\hline \multicolumn{2}{|c|}{ Hepatitis Status n (\%) } \\
\hline \multicolumn{2}{|c|}{ HBV } \\
\hline Positive & $16(9.5)$ \\
\hline Negative & $152(90.5)$ \\
\hline \multicolumn{2}{|l|}{$\boldsymbol{H C V}$} \\
\hline Positive & $13(7.7)$ \\
\hline Negative & $155(92.3)$ \\
\hline \multicolumn{2}{|c|}{$H B V+H C V$} \\
\hline Positive & $1(0.6)$ \\
\hline Negative & $167(99.4)$ \\
\hline
\end{tabular}

HBV=hepatitis B virus; $\mathrm{HCV}=$ hepatitis $C$ virus

Table 2 shows the factors associated with HBV and $\mathrm{HCV}$ infection among the study participants. None of the risk factors showed a significant association with HBV infection. However, blood transfusion $(\mathrm{OR}=13.91 ; \mathrm{P}=0.012)$, tattooing and sharing of nee- dles $(\mathrm{OR}=7.21 ; \mathrm{P}=0.004)$ were associated with $\mathrm{HCV}$ infection. Factors such as diagnosis with STD'S, history of healthcare needle stick injury, exposure to human blood, and family history of HCV were not significantly associated with HCV infection ( $\mathrm{P}>0.05)$.

Table 2: Factors predisposing participants to hepatitis $\mathbf{B}$ and hepatitis $\mathbf{C}$ infections

\begin{tabular}{|c|c|c|c|c|}
\hline \multirow[t]{2}{*}{ Variable } & \multicolumn{2}{|l|}{ HBV } & \multicolumn{2}{|l|}{$\mathrm{HCV}$} \\
\hline & OR $(95 \%$ CI) & $\begin{array}{l}\text { P- } \\
\text { value }\end{array}$ & OR $(95 \%$ CI) & P-value \\
\hline \multicolumn{5}{|c|}{ Diagnosed with STD's } \\
\hline Yes & $\begin{array}{l}1.93(0.66- \\
5.69)\end{array}$ & 0.231 & $2.83(0.89-8.97)$ & 0.077 \\
\hline No $*$ & $1^{*}$ & & $1^{*}$ & \\
\hline \multicolumn{5}{|c|}{ Multiple Sexual partners } \\
\hline Yes* & $1 *$ & & $1^{*}$ & \\
\hline No & $1^{*}$ & & & \\
\hline \multicolumn{5}{|c|}{ Receipt of clotting factor concentrates } \\
\hline Yes* & $\begin{array}{l}1 * \\
0.11(0.00-\end{array}$ & & $1^{*}$ & \\
\hline \multicolumn{5}{|c|}{$\begin{array}{l}\text { Contact with blood/open sores of } \\
\text { infected person }\end{array}$} \\
\hline Yes* & $\begin{array}{l}1^{*} \\
0.11(0.00-\end{array}$ & & $1^{*}$ & \\
\hline No & 5.63) & 0.270 & $0.09(0.00-4.55)$ & 0.226 \\
\hline
\end{tabular}


Due to the fact that most of the participants answered no to exposure to some risk factors (multiple sexual partners, haemodialysis treatment, usage of illegal drugs, sharing of toothbrush with HCV affected person, receiving blood clotting factors concentrates and contact with blood or open sores), no association was found to exist between such factors and HCV infection.

\section{Discussion}

$\mathrm{HBV}$ and HCV infections are both contagious diseases that can be transmitted vertically from mothers to their neonates or horizontally through blood products and body secretions ${ }^{5}$. This study determined the prevalence and risk factors associated with hepatitis $B$ and $C$ infection among pregnant women in the Ashanti Akimnorth municipality in the Ashanti region of Ghana. The study revealed $9.5 \%$ and $7.7 \%$ prevalence of hepatitis $\mathrm{B}$ and hepatitis $\mathrm{C}$ infection respectively among the participants. Only one participant $(0.6 \%)$ was a carrier of both viruses. Also, no association was found between hepatitis B infections and the risk factors. Blood transfusion, tattooing, body piercing and sharing of needles were associated with transmission of hepatitis $C$ virus infection among the participants.

The prevalence observed in this study is consistent with the findings of earlier studies which reported a higher hepatitis $\mathrm{B}$ infection rate than hepatitis $\mathrm{C}$ among pregnant women in Nigeria ${ }^{12}$. The above findings are also similar to the study of Murad et $\mathrm{al}^{13}$, who recorded a prevalence of $10.8 \%, 8.5 \%$ and $0 \%$ of $\mathrm{HBV}, \mathrm{HCV}$ and HBV-HCV co-infection respectively among 400 participants in Saana Yemen. However, our prevalence is higher than the $5 \%$ and less than one percent recorded in studies in Sudan ${ }^{7}$. The prevalence in our study is higher because we used immunochromatographic methods whereas ELISA technique was used in the Sudanese study. Immunochromatographic methods have lower specificity compared to the more specific ELISA techniques. In contrast with earlier studies in Sudan and Malawi ${ }^{14} 0.6 \%$ of our participants had both HCV and $\mathrm{HBV}$ infection.

The prevalence of hepatitis $\mathrm{C}$ infection in this study was higher $(7.7 \%)$ than the prevalence $(0.2 \%$ and $6.25 \%$ ) reported in Lorestan (West of Iran) and Ahvaz by Mohebbi et al., ${ }^{5}$ and Motlagh et al, ${ }^{15}$ respectively. These inconsistencies could be attributed to the differences in sample size as well as the fact that Mohebbi et al., conducted their study across multiple centres in rural and urban communities whereas our single-centre study was conducted in a predominantly rural commu- nity. Moreover, in the cross-sectional study by Mohebbi et al, ${ }^{5}$ samples were first screened for anti-HBc and anti-HCV using commercially available ELISA kits before those which were reactive for anti-HBc were tested for HBsAg. Similarly, the prevalence rate of HBV infection recorded in this study is higher than that observed in earlier studies among pregnant women in Sudan ${ }^{16}$, Saudi Arabia ${ }^{17}$ and Libya ${ }^{18}$. Geographical differences have been identified as the main reason for the variation of seroprevalence rates of $\mathrm{HBV}$ infection among pregnant women in different countries ${ }^{19}$. Furthermore, as in the studies in Lorestan and Ahaz, positive cases in Egypt, Saudi Arabia and Libya were confirmed with ELISA techniques. However, studies conducted by Eke et al, ${ }^{20}$ from Nigeria recorded a prevalence $(8.3 \%)$ comparable with what is recorded in our study.

In consonance with earlier studies ${ }^{21}$, we observed a significant association between some risk factors (tatooing and body piercing, history of sharing of hypodermic needles and blood transfusion) and HCV infection. Ward et al., ${ }^{21}$ had earlier identified an association between illicit drug use and body piercing (chiefly for ear rings) and HCV infection in the multiethnic population in London. In agreement with the findings of Eke et $\mathrm{al}^{20}$ and Akani et al, ${ }^{22}$ from studies conducted in Nnewi and Port Harcourt respectively, we recorded no significant association between hepatitis B infection and the risk factors. Interestingly, this observation contradicts the results of studies conducted in Nigeria and Palestine ${ }^{23,24}$. Though no reason could readily be assigned for this observation, the small sample size employed in this study coupled with the method of testing for the infection could account for the lack of association between hepatitis B infection and the risk factors.

The outcome of this study justifies the establishment of a national HBV and HCV screening program for all pregnant women in antenatal clinics throughout Ghana. In addition, a national policy to vaccinate all pregnant women who test negative for hepatitis B must be adopted so as to reduce the risk of mother to child transmission within the population. Although this study is relevant it has major limitations. Investigation into a similar population of non-pregnant women to compare the findings was not done. Also, the study did not employ ELISA for the sero-analysis but rather used rapid test strips which may not yield 100\% accuracy especially for HCV. Furthermore, the viral load was not determined for HBV and HCV positive pregnant women.

\section{Conclusion}

The prevalence of $\mathrm{HBV}$ and HCV infection in this 
study was $9.5 \%$ and $7.7 \%$ respectively. History of sharing hypodermic needles, tattooing and body piercing, and blood transfusion were associated with HCV infection. The Ghana Health Service policy of screening all pregnant women in Ghana during their routine antenatal visit is therefore justified and a policy to vaccinate women who test negative for HBV must be promulgated to reduce the future risk of mother to child transmission.

\section{Acknowledgement}

The authors are grateful to the staff of the laboratory and antenatal departments of the Agogo Presbyterian hospital

\section{Competing interests}

None declared

\section{References}

1. Lok, A.S., Chronic hepatitis B. N Engl J Med, 2002. 346(22): p. 1682-3.

2. Drosten, C., Nippraschk, T., Manegold, C., Meisel, H., Brixner, V., Roth, W.K., et al., Prevalence of hepatitis $\mathrm{B}$ virus DNA in anti-HBc-positive/ $\mathrm{HBsAg}$-negative sera correlates with HCV but not HIV serostatus. J Clin Virol, 2004. 29(1): p. 59-68.

3. Parry, J., At last a global response to viral hepatitis. Bull World Health Organ, 2010. 88(11): p. 801-2.

4. Te, H.S.Jensen, D.M., Epidemiology of hepatitis B and C viruses: a global overview. Clin Liver Dis, 2010. 14(1): p. 1-21, vii.

5. Mohebbi, S.R., Sanati, A., Cheraghipour, K., Rostami Nejad, M., Shalmani, H.M.,Zali, M.R., Hepatitis C and hepatitis $\mathrm{B}$ virus infection: epidemiology and risk factors in a large cohort of pregnant women in Lorestan, West of Iran. Hepat Mon, 2012. 11(9): p. 736-9.

6. Petrova, M.Kamburov, V., Breastfeeding and chronic HBV infection: clinical and social implications. World J Gastroenterol, 2010. 16(40): p. 5042-6.

7. Elsheikh, R.M., Daak, A.A., Elsheikh, M.A., Karsany, M.S.,Adam, I., Hepatitis B virus and hepatitis C virus in pregnant Sudanese women. Virol J, 2007. 4: p. 104.

8. Armstrong, G.L., Arase, Y., Ikeda, K., Murashima, N., Chayama, K., Tsubota, A., et al., The prevalence of hepatitis C virus infection in the United States, 1999 through 2002. Ann Intern Med 2006. 144: p. 705-714.

9. Hieber, J.P., Dalton, D., Shorey, J.,Combes, B., Hepatitis and pregnancy. J Pediatr, 1977. 91(4): p. 545-9.

10. Sookoian, S., Liver disease during pregnancy: acute viral hepatitis. Ann Hepatol, 2006. 5(3): p. 231-6.

11. Jonas, M.M., Hepatitis B and pregnancy: an under- estimated issue. Liver Int, 2009. 29 Suppl 1: p. 133-9. 12. Ugbebor, O., Aigbirior, M., Osazuwa, F., Enabudoso, E.,Zabayo, O., The prevalence of hepatitis B and C viral infections among pregnant women. $N A m \mathrm{~J} \mathrm{Med}$ Sci, 2011. 3(5): p. 238-41.

13. Murad, E.A., Babiker, S.M., Gasim, G.I., Rayis, D.A.,Adam, I., Epidemiology of hepatitis B and hepatitis $C$ virus infections in pregnant women in Sana'a, Yemen. BMC Pregnancy Childbirth, 2013. 13: p. 127.

14. Ahmed,S.D., Cuevas, L.E., Brabin, B.J., Kazembe, P., Broadhead, R., Verhoeff, F.H., et al., Seroprevalence of hepatitis B and C and HIV in Malawian pregnant women. J Infect, 1998. 37(3): p. 248-51.

15. Motlagh, M., Makvandi, M.Jalali, M., Prevalence of anti-HCV among pregnant women. J Qazvin Univ Med Sci, 2001. 5(2): p. 59-63.

16. EL-Shabrawi, M., Mohamed, M., El Din Hamdi, M., Ehab, M., Khamiss, S.,EL Karasky, H., Prevalence of Hepatitis B Virus Infection among Egyptian Pregnant Women - A Single Center. Study international journal of tropical disease \& health, 2013. 3(2): p. 157-168.

17. Alrowaily, M.A., Abolfotouh, M.A.,Ferwanah, M.S., Hepatitis B virus sero-prevalence among pregnant females in Saudi Arabia. Saudi J Gastroenterol, 2008. 14(2): p. $70-2$

18. El-Magrahe, H., Furarah, A.R., El-Figih, K., El-Urshfany, S.,Ghenghesh, K.S., Maternal and neonatal seroprevalence of Hepatitis B surface antigen (HBsAg) in Tripoli, Libya. J Infect Dev Ctries, 2010. 4(3): p. 168-70. 19. Vazquez-Martinez,J.L., Coreno-Juarez, M.O., Montano-Estrada, L.F., Attlan, M.,Gomez-Dantes, H., Seroprevalence of hepatitis B in pregnant women in Mexico. Salud Publica Mex, 2003. 45(3): p. 165-70.

20. Eke, A.C., Eke, U.A., Okafor, C.I., Ezebialu, I.U.,Ogbuagu, C., Prevalence, correlates and pattern of hepatitis B surface antigen in a low resource setting. Virol J, 2011. 8: p. 12.

21. Ward, C., Tudor-Williams, G., Cotzias, T., Hargreaves, S., Regan, L.,Foster, G.R., Prevalence of hepatitis $\mathrm{C}$ among pregnant women attending an inner London obstetric department: uptake and acceptability of named antenatal testing. Gut, 2000. 47(2): p. 277-80.

22. Akani, C.I., Ojule, A.C., Opurum, H.C.,Ejilemele, A.A., Sero-prevalence of hepatitis B surface antigen (HBsAg) in pregnant women in Port Harcourt, Nigeria. Niger Postgrad Med J, 2005. 12(4): p. 266-70.

23. Nazzal, Z.Sobuh, I., Risk factors of hepatitis B transmission in northern Palestine: a case - control study. BMC Res Notes, 2014. 7: p. 190.

24. Obienu, O., Nwokediuko, S., Malu, A.,Lesi, O.A., Risk factors for hepatitis $\mathrm{C}$ virus transmission obscure in nigerian patients. Gastroenterol Res Pract, 2011. 